\title{
The evaluation of surgical reconstruction for intermittent claudication by the Walking Impairment Questionnaire
}

\section{Avaliação da reconstrução cirúrgica para claudicação intermitente pelo Walking Impairment Questionnaire}

Masaya Nakashima', Kazuo Yamaguchi

\begin{abstract}
Background: No standards reflecting the quality of life (QOL) and activity of daily living (ADL) in postoperative clinical course have been validated in the area of vascular disease. The Walking Impairment Questionnaire (WIQ) is a disease-specific questionnaire that evaluates patients with intermittent claudication due to arteriosclerosis obliterans (ASO). The WIQ uses four subscales: pain severity, walking distance, walking speed, and stair climbing while walking.

Objective: To evaluate the correlation between postoperative arterial blood flow and the Japanese edition of the WIQ.

Methods: Thirty-one patients ( 47 limbs) with intermittent claudication who had been subjected to lower limb surgical arterial reconstruction were assessed by WIQ, and compared with Ankle-Brachial Pressure Index (ABPI) and angiography.

Results: A significant increase in the WIQ score was identified in walking pain (26 versus $89.5, p<0.001$ ), walking distance $(13.1$ versus $83.3, p<0.001)$, walking speed (10 versus 46, $\mathrm{p}<0.001)$, and stair climbing $(6.2$ versus $79, \mathrm{p}<0.001)$. The correlation coefficient between the increase in postoperative $\mathrm{ABPI}$ and the WIQ score was $\mathrm{R}^{2}=0.1889$, which shows weak correlation. The correlation between blood flow obstruction due to the postoperative bypass that was scored by angiography and WIQ score was $R^{2}=0.3894$, which shows moderate correlation.

Conclusion: An improvement in the Japanese edition of the WIQ score was correlated not only with the patients' QOL after bypass revascularization but also with the rate of increase of postoperative $A B P I$ and image findings, such as the postoperative angiography.

Keywords: Intermittent claudication; arteriosclerosis obliterans; vascular surgery.

\section{Resumo}

Introdução: Nenhum padrão de qualidade de vida e atividades diárias no período pós-operatório já foi validado na área de doenças vasculares. O Walking Impairment Questionnaire (WIQ) é um questionário específico para pacientes com claudicação intermitente devido à aterosclerose obliterante. O WIQ se baseia em quatro subescalas: intensidade da dor, distância caminhada, velocidade de caminhada e subir degraus durante caminhada.

Objetivo: Avaliar a correlação entre fluxo sanguíneo periférico pós-operatório e a edição japonesa do WIQ.

Métodos: Trinta e um pacientes (totalizando 47 membros inferiores) com claudicação intermitente que se submeteram à reconstrução arterial cirúrgica foram avaliados pelo WIQ e comparados por meio do índice de pressão tornozelo-braço (ITB) e angiografia.

Resultados: Um aumento significativo no escore do WIQ foi observado em relação à dor durante caminhada (26 versus 89,5, $p<0,001)$, distância caminhada (13,1 versus 83,3, $p<0,001$ ), velocidade da caminhada (10 versus $46, p<0,001$ ) e ato de subir escadas $(6,2$ versus 79, $p<0,001)$. O coeficiente de correlação entre o aumento no ITB pós-operatório e o escore WIQ foi $R^{2}=0,1889$, demonstrando correlação baixa. A correlação entre obstrução do fluxo sanguíneo devido ao bypass pós-operatório avaliado por angiografia e WIQ foi $R^{2}=0,3894$, o que revela uma correlação moderada.

Conclusão: Uma melhora na edição japonesa do escore WIQ esteve correlacionada não apenas com a qualidade de vida dos pacientes após revascularização com bypass, mas também com a taxa de aumento no ITB pós-operatório e achados imaginológicos, como a angiografia pósoperatória.
\end{abstract}

Palavras-chave: Intermittent claudication; arteriosclerose obliterante; cirurgia vascular. 


\section{Introduction}

The current treatment of arteriosclerosis obliterans (ASO) is influenced by several factors, depending on the examination equipment, endovascular treatment equipment, staff, and the choice of surgical procedures. Furthermore, objective criteria for treatment have not been specified for angioplasty or bypass surgery, and no indices reflecting the quality of life (QOL) and activity of daily living (ADL) in postoperative clinical course have been validated. The Walking Impairment Questionnaire (WIQ) is a disease-specific questionnaire that evaluates patients with intermittent claudication (IC) due to ASO, with four subscales: pain severity, walking distance, walking speed, and stair climbing while walking ${ }^{1}$. In this study, we examined the therapeutic effect of lower limb revascularization procedures by evaluating QOL and $\mathrm{ADL}$ after bypass surgery with the Japanese edition of the WIQ and compared it to Ankle Brachial Pressure Index (ABPI) and angiography.

\section{Methods}

The cohort consisted of 31 patients with IC due to ASO, who underwent lower limb bypass surgery between December 2004 and February 2008. There were 27 males and 4 females, with a mean age of $72.6 \pm 3.31$ years ( $54-81$ years), for a total of 47 limbs. The Japanese edition of the WIQ was used as the QOL survey. The WIQ was administered at the office before surgery and at four months after surgery. By examining ABPI and angiography (Computerized tomography angiography - CTA or magnetic ressonance angiography - MRA) at the same time, the WIQ score and graft patency outcomes were compared. Underlying diseases are listed in Table 1.

Synthetic grafts were used in all axillo-femoral and femoro-femoral bypasses. Autogenous saphenous vein was

Table1 - Patients characteristics

\begin{tabular}{lc}
\hline & Total population $(\mathrm{n}=31)$ \\
\hline Mean age (y) & $72.6 \pm 3.31$ \\
Male/Female & $27 / 4$ \\
Cigarette smoking (\%) & 87 \\
Hypertension (\%) & 77 \\
Hypercholesterolemia (\%) & 45 \\
Diabetes mellitus (\%) & 52 \\
Ischemic heart disease (\%) & 29 \\
Cerebrovascular disease (\%) & 19 \\
\hline
\end{tabular}

used in 17 out of 19 femoro-popliteal bypasses and in 5 out of 7 ilio-femoral bypasses.

Before surgery and at four months after surgery, the Japanese edition of WIQ was administered at the office. ABPI was measured at the same time, and the differences between the preoperative and postoperative WIQ scores were compared with ABPI by plotting them on a graph (Figure 1). CTA was performed for objective evaluation of lower limb blood flow. In patients with impaired renal function, the less invasive MRA was used. Bypass blood flow stenosis/obstruction was evaluated by a radiologist by visual scoring, as follows: 4 - excellent $(0 \%) ; 3$ - good (1-40\%); 2 - fair (40-70\%); 1 - poor (70-99\%); and 0 occlusion (100\%). A graph was plotted with the postoperative angiography and differences between preoperative and postoperative WIQ total scores (Figure 2).

\section{Statistical analysis}

Continuous data were expressed as the mean \pm standard deviation (SD). Differences in the preand postoperative WIQ score were tested with a MannWhitney model. Pearsons bivariate correlations were used to examine the relationship between the patients ABPI and the WIQ total score, and between angiography and the WIQ total score.

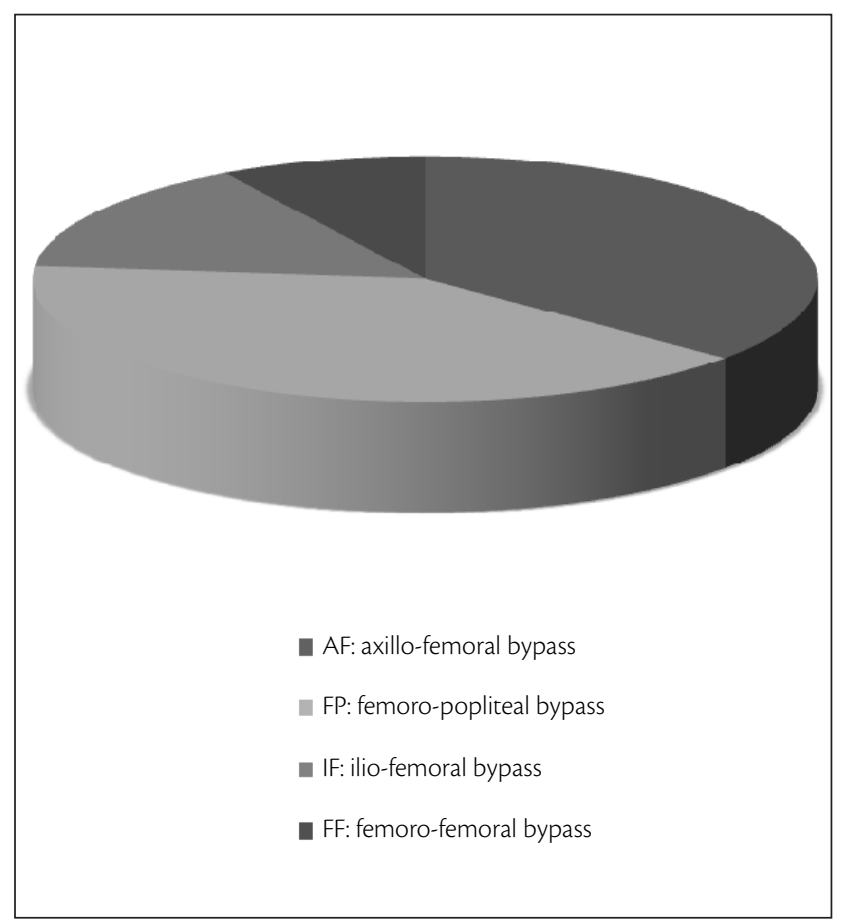

Figure 1 - Operation technique 


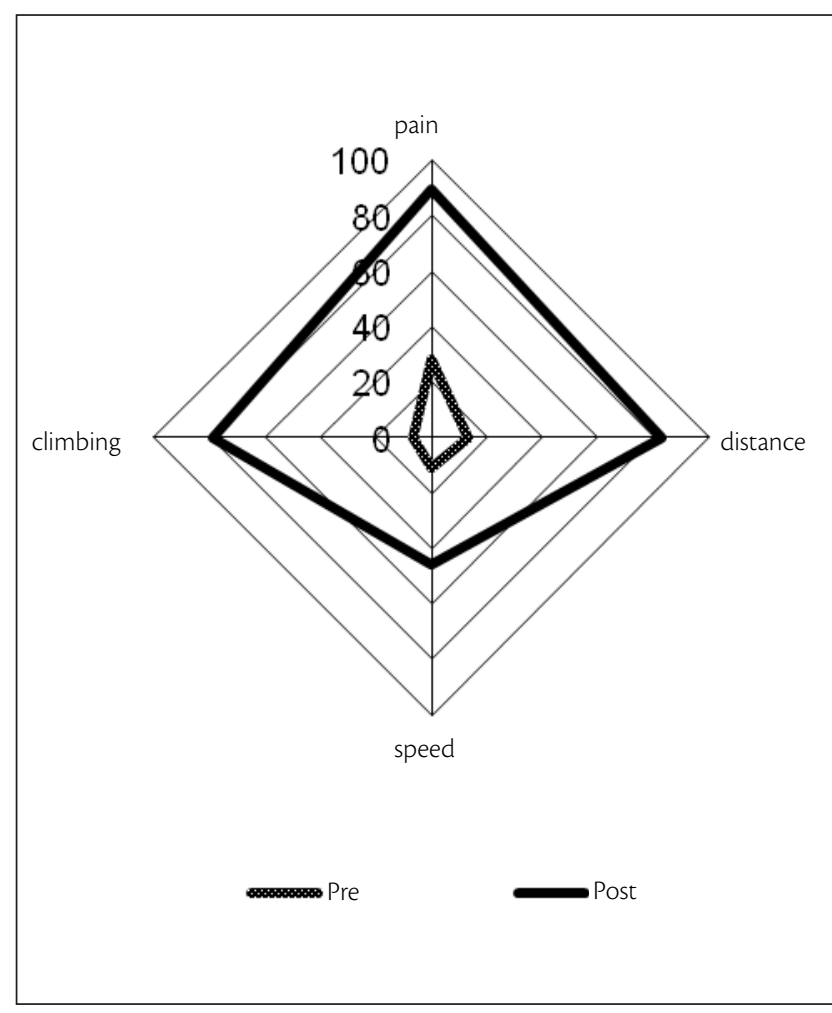

Figure 2 - Impairment questionnaire (IQ) score in pre and postoperation

\section{Results}

A comparison of the WIQ scores before and after the revascularization procedure is shown in a graph (Figure 2). In all cases, an increase in the score was observed in walking pain ( 26 versus $89.5, \mathrm{p}<0.001)$; walking distance ( 13.1 versus 83.3, $\mathrm{p}<0.001)$; walking speed ( 10 versus $46, \mathrm{p}<0.001)$ and stair climbing $(6.2$ versus $79, \mathrm{p}<0.001)$.

The average preoperative ABPI was $0.44 \pm 0.13$ (0$0.66)$ and the average postoperative ABPI was $0.73 \pm 0.12$ (0.51-1.4). The postoperative increase in ABPI (\%) and differences between the preoperative and postoperative WIQ total scores were compared (Figure 3). The correlation coefficient between the increase in postoperative $\mathrm{ABPI}$ and the WIQ score was $\mathrm{R}^{2}=0.1889$, which shows weak correlation.

An evaluation of the blood flow was performed by visually comparing the preoperative angiography with the postoperative angiography. The differences between preoperative and postoperative WIQ total scores were plotted against the angiographic findings (Figure 4). The correlation coefficient between blood flow as scored at angiography and the WIQ score was $\mathrm{R}^{2}=0.3894$, which shows a moderate correlation.

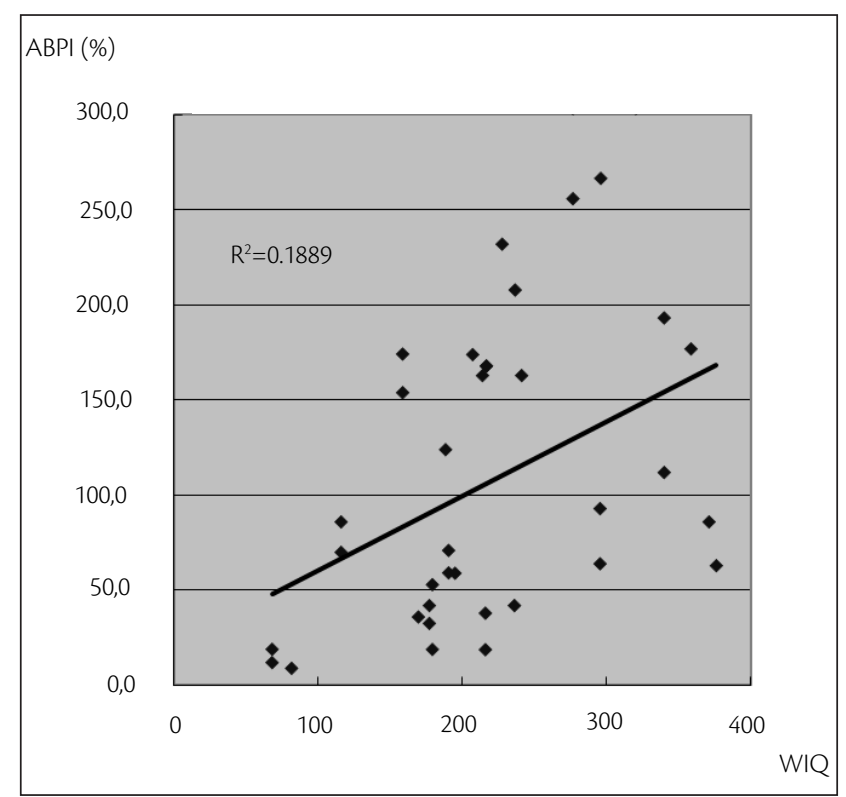

Figure 3 - Correlation between Ankle-Brachial Pressure Index (ABPI) and Walking Impairment Questionnaire (WIQ)

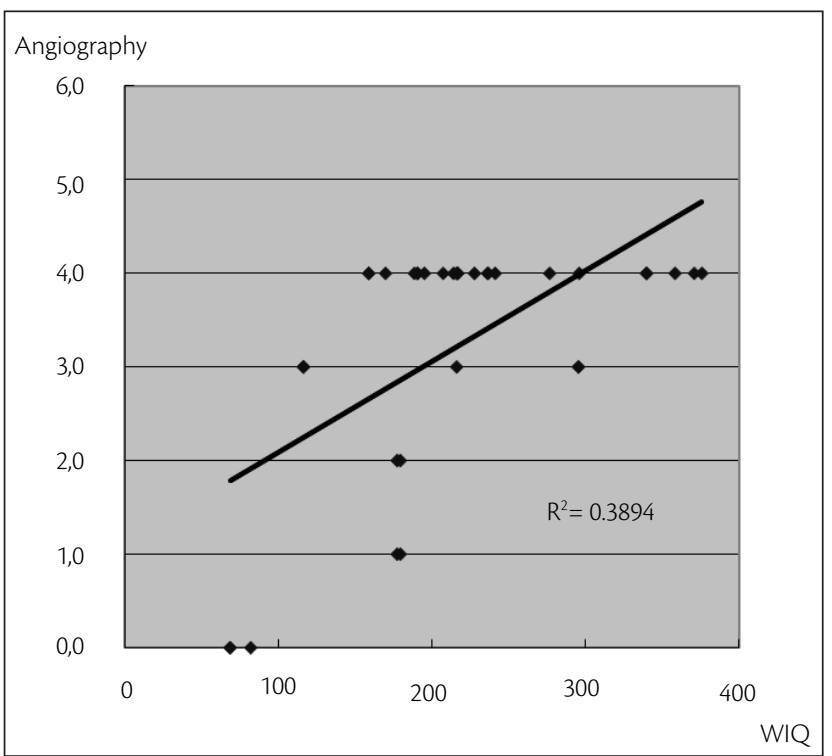

Figure 4 - Collaboration between Walking Impairment Questionnaire (WIQ) and angiography

\section{Discussion}

The current situation in patients with ASO is that the evaluation of walking impairment severity, with a focus on the patients' daily life, greatly depends on the rough walking distance reported by patients. The patients QOL is the most important factor in an evaluation of the severity of ischemic limbs. Ischemia is generally evaluated by objective methods, such 
as ABPI, treadmill walking load, near-infrared spectroscopy (NIRS) and skin perfusion pressure by laser Doppler. Those methods actually vary from one facility to another, making it difficult to compare different reports. A typical questionnaire that has been used is the Short Form 36 (SF-36), which evaluates health-related QOL (HRQOL: Health Related Quality of Life $)^{2}$. It is a comprehensive measure that can examine two factors: physical and mental health performances. It consists of 36 questions covering 8 fields, including the physical function, role-physical function, bodily pain, general health, vitality, social function, role-emotional function, and mental health, and can be used to score QOL ${ }^{2}$. However, because it scores general health condition, it is also used for other major chronic diseases and lacks specificity for peripheral artery disease (PAD). The WIQ, which was used for the evaluation of the QOL of patients after bypass surgery in this study, is a disease-specific questionnaire that evaluates patients with IC with four subscales: pain severity, walking distance, walking speed, and stair climbing while walking. Based on the defined scoring method, four subscales are calculated, and by scoring them from 0 to 100 , higher values represent a better walking condition. WIQ acts as an outcome index before and after the treatment of symptoms, and daily life information - which cannot be obtained via treadmill exercise test - can be thus obtained ${ }^{1,3,4}$. Menard et al. evaluated patients with PAD after exercise rehabilitative therapy using SF-36 and the WIQ, thus indicating that the WIQ showed an apparent improvement in walking distance, walking speed, and stair climbing 5 . WIQ is the most specific questionnaire for documenting the qualitative deficits of the patient with $\mathrm{IC}^{6-8}$. However, the current situation is that, even though it has been translated into various languages, such as French and German, the Japanese edition of the WIQ has not yet been widely used ${ }^{9}$.

In this study, all of our patients underwent surgery only for IC, but contrary to our expectation, as in Long et al., the correlation between differences in WIQ score and the rate of increase in ABPI was weak ${ }^{6}$. It is believed that this unexpected finding is explained by the association of several factors, such as the small number of patients, the patients' mean old age, underlying diseases and daily life before surgery. In the background of our subject patients in this study, as many as $52 \%$ were diabetic patients, and several ones had indefinite complaints, such as neurological symptoms in the lower limbs, before surgery. Moreover, three patients showed almost no increase in the scores for pain severity and walking speed, but walking distance and stair climbing greatly improved after bypass surgery.

The postoperative angiographic visual evaluation of the bypass blood flow and the WIQ score showed moderate correlation. The rate of increase in the blood flow and postoperative WIQ increased in all cases in this study, but in two cases with bypass stenosis, the unexpected increase in WIQ was 25 versus 93.5 and 135.5 versus 217.5, with a limited WIQ total score increasing by less than 100. In two cases with bypass obstruction, when the WIQ at one month following surgery and the WIQ after four months were compared, the WIQ score dramatically decreased, and the postoperative ABPI also decreased.

Therefore, unlike SF-36, we can say that the WIQ is very useful for postoperative evaluation, because the inquiry examination time is short and it is disease-specific. Moreover, because the Japanese edition of the WIQ that we used in this study is an examination that can be performed briefly within a short period at a doctor's office, we therefore expected that WIQ may be used not only as a mere outcome index of symptoms but it may also be utilized in ASO screening. From the perspective of medical economics, it is believed that it would be highly valuable to conduct the WIQ first at a doctor's office rather than immediately performing imaging tests such as angiography for screening and after surgery. To popularize and standardize the WIQ in the future, it will be necessary to examine further cases, including their outcomes in the remote phase.

There are several limitations associated with this study. For example, we unexpectedly performed a large number of extra-anatomical bypasses (axillo-femoral bypass, femoro-femoral bypass) at our institution. In general, extra-anatomical bypass is not a standard operation technique for patients with IC. Regrettably, there was likely some bias for this selection of ASO patients. In our study, $52 \%$ of the patients had a history of diabetes mellitus, and some of them also had a history of several sessions of endovascular therapy (EVT). Many sessions of EVT were thus performed in four patients, and three of them had severe calcification of the iliac artery and the aorta. Furthermore, one patient had a history of iliopsoas abscess. We therefore selected an axillo-femoral bypass in this case in order to avoid any postoperative infections. For the reasons stated above, a number of extra-anatomical bypasses, which had not been planned, were therefore performed in this study. Although our concept regarding this study was to achieve an improved postoperative walking functioning and a better limb blood flow, the various factors observed in highrisk patients are considered to support the selection of these operative procedures. Finally, the number of patients in this study was relatively small. We evaluated some cases of postoperative blood flow by MRA. It may therefore not be appropriate to evaluate the total limb blood flow. However, 
the main objective of this study was to assess the postoperative walking functioning by the WIQ. It will therefore be necessary to examine further cases.

\section{Conclusion}

An improvement in the Japanese edition of the WIQ score was correlated not only with the patients' QOL after bypass revascularization but also with the rate of increase of postoperative ABPI and image findings such as the postoperative angiography. In cases without blood flow problems after reconstruction, a significant improvement could generally be observed in the QOL, especially regarding the walking condition. The utilization of the WIQ is highly useful as a method not only for evaluating symptoms such as IC but also for comprehensively evaluating walking impairment of patients after vascular surgery.

\section{References}

1. Ikeda S, Kobayashi M, Shigematsu H, et al. Development of the Japanese version of Walking Impairment questionnaire. J Jpn Coll Angiol. 2005;45:233-40

2. Ware Jr. JE, Sherbourne CD. The MOS 36-item short-form health survey (SF-36). Med Care. 1992;30:473-83.

3. Menard JR, Smith HE, Riebe D, Braun CM, Blissmer B, Patterson RB. Long-term results of peripheral arterial disease rehabilitation. J Vasc Surg. 2004;39:1186-92.

4. Coyne KS, Margolis MK, Gilchrist KA, et al. Evaluating effects of method of administration on Walking Impairment Questionnaire. J Vasc Surg. 2003;38:296-304.
5. Long J, Modrall JG, Parker BJ, Swann A, Welborn MB 3rd, Anthony T. Correlation between ankle-brachial index, symptoms, and health-related quality of life in patients with peripheral vascular disease. J Vasc Surg. 2004;39:723-7.

6. Nicolaï SP, Kruidener LM, Rouwet EV, Grafiusa K, Prins M, Teijink JA. The walking impairment questionnaire: an effective tool to assess the effect of treatment in patients with intermittent claudication. J Vasc Surg 2009;50:89-94.

7. Myers SA, Johanning JM, Stergiou N, Lynch TG, Longo GM, Pipinos II. Claudication distances and the Walking Impairment Questionnaire best describe the ambulatory limitations in patients with symptomatic peripheral arterial disease. I Vasc Surg. 2008; $47: 550-5$.

8. Cunha-Filho IT, Pereira DAG, Carvalho AMB, Campedeli L, Soares $M$, Freitas JS. Confiabilidade de testes de caminhada em paciente claudicantes: estudo piloto. J Vasc Bras 2007;7:106-11.

9. Ritti-Dias RM, Gobbo LA, Cucato GG, et al. Translation and validation of the walking impairment questionnaire in Brazilian subjects with intermittent claudication. Arq Bras Cardiol. 2009;92:136-49.

Correspondence:
Masaya Nakashima
Department of Cardiovascular Surgery, 1-1 - Sannomaru, 4-chome, Naka-ku,
Nagoya, Aichi, Japan, 460-0001
Phone: (81) 52-951-1111; Fax: (81) 52-951-9075
E-mail: masaya81973@gmail.com
Author's contribution
Conception and design: MN, KY
Analysis and interpretation: MN, KY
Data collection: MN, KY
Writing the article: MN, KY
Critical revision of the article: MN, KY
Final approval of the article*: MN, KY
Statistical analysis: MN, KY
General responsibility for the study: MN, KY
*All authors have read and approved the final version of the article submitted to J
Vasc Bras.

